\title{
¿La dignidad cabe en un bolsillo? Reflexiones sobre la protección de la mujer embarazada, frente al delito de discriminación en Colombia
}

\author{
Does dignity fit in a pocket? \\ Reflections on the Protection of Pregnant Women, Against the Crime of \\ Discrimination in Colombia
}

José Manuel Herrera Rodríguez ${ }^{*}$

*Abogado Grancolombiano. Magister en Derechos Humanos y Justicia Transicional. gerencia@hrservicioslegalesabogados.com

Fecha de recepción: Agosto de 2019

Fecha de aprobación: marzo de 2020

Para citar este artículo / To reference this article ¿La dignidad cabe en un bolsillo? Reflexiones sobre la protección de la mujer embarazada, frente al delito de discriminación en Colombia. Inciso, 22(1); 75-101.

DOI: http://dx.doi.org/10.18634/incj.22v.1i.1032

\begin{abstract}
Resumen
El presente artículo analiza un posible déficit en la protección de las trabajadoras gestantes cuando son discriminadas y coartadas en su derecho al trabajo por su condición de gravidez. Al momento de obtener una sentencia en la jurisdicción laboral o constitucional solo se les entrega un dinero como indemnización o reinstalación, sin que exista ningún tipo de impulso procesal de parte de dichas jurisdicciones hacia la investigación de una conducta penal como la discriminación, en defensa de la dignidad humana. La metodología se basara en el análisis de las normas existentes, la jurisprudencia y la información obtenida vía derecho de petición de parte de la Fiscalía General De La Nación, desde la visión de la criminología como una justificación a la existencia y procedencia de una investigación penal en protección de la dignidad humana de estas trabajadoras, a fin de poder encontrar puntos de encuentro que justifiquen el impulso de una investigación penal desde la jurisdicción laboral por el delito de discriminación, cuando el juez laboral encuentre argumentos para tal fin. Desde la metodología y el análisis propuestos, es posible encontrar una solución a la falta de sensibilidad en los funcionarios del reparto de la FGN, frente a la necesidad de seguir con la persecución penal, cuando proviene del despido injusto de una trabajadora en estado de gravidez.
\end{abstract}


Palabras clave: delito, dignidad, discriminación, trabajadora gestante.

\begin{abstract}
This article analyzes a possible deficit in the protection of pregnant women workers when they are discriminated against and restricted in their right to work due to their condition of pregnancy. At the time of obtaining a sentence in the labor or constitutional jurisdiction, they are only given a money as compensation or reinstatement, without there being any type of procedural impulse on the part of said jurisdictions towards the investigation of criminal conduct such as discrimination, in defense of human dignity. The methodology will be based on the analysis of the existing norms, the jurisprudence and the information obtained via the right of petition from the Office of the Attorney General of the Nation, from the perspective of criminology as a justification for the existence and origin of a criminal investigation. in protection of the human dignity of these workers, in order to find meeting points that justify the promotion of a criminal investigation from the labor jurisdiction for the crime of discrimination, when the labor judge finds arguments for this purpose. From the proposed methodology and analysis, it is possible to find a solution to the lack of sensitivity in the FGN distribution officials, in the face of the need to continue with the criminal prosecution, when it comes from the unfair dismissal of a pregnant woman.
\end{abstract}

Keywords: crime, dignity, discrimination, pregnant worker.

\title{
Introducción
}

Desde la adopción de la Declaración Universal de Derechos Humanos (Asamblea General de la ONU, 1948), se ha prohibido el ejercicio de discriminación: "Artículo 2. Toda persona tiene los derechos y libertades proclamados en esta Declaración, sin distinción alguna de raza, color, sexo, idioma, religión, opinión política o de cualquier otra índole, origen nacional o social, posición económica, nacimiento o cualquier otra condición" (Asamblea General. 1948, p2) y se ha luchado por incluir en las legislaciones internas de los países, reglas que prevengan tales conductas y garanticen el ejercicio de los derechos fundamentales individuales de las personas. En consonancia con lo anterior, la ley colombiana adoptó mediante la Ley 22 de 1981 la Convención Internacional sobre la Eliminación de todas las formas de discriminación Racial (Convención. 1965), posteriormente, la Constitución Política de Colombia (Constituyente, 1991), incluyó en su articulado principal la voluntad de proteger la dignidad humana tal y como reflejan los artículos 1, 5 y 13 , y bajo tales parámetros, se han venido adoptando, una serie de leyes que previenen al ciudadano en la comisión de discriminación, hasta llegar a la Ley 1482 de 2011(Congreso de Colombia, 2011), modificada por la Ley 1752 de 2015 (Congreso, 2015), leyes que incluyeron en el Código Penal Colombiano, los artículos 134 A, 134B y 134C (Código Penal, 2000), donde se relacionan los actos de discriminación como delitos autónomos (FGN. 2017).

Sin embargo, la protección que brinda la jurisdicción laboral y constitucional, a la trabajadora en estado de embarazo, ha cooptado la atención de la reparación, al limitarla al tema económico, desconociéndose así, la existencia implícita de una posible comisión del delito de discriminación, cuando un empleador 
despide a una trabajadora en estado de gestación por el solo hecho de estar embarazada, siendo esta, una manera de violencia contra la mujer en el ámbito laboral, que transgrede todas las legislaciones que ha desarrollado Colombia en prevención contra la discriminación.

El presente artículo, pretende contribuir con el análisis de un posible déficit en la protección de las trabajadoras en gravidez, cuando contra ellas se les discrimina y se les coarta el derecho al trabajo, por su condición de embarazo, al momento de obtener una sentencia en la jurisdicción laboral o constitucional que les devuelve el empleo o les entrega un dinero como indemnización, sin que exista ningún tipo de impulso procesal de parte de dichas jurisdicciones, hacia la investigación de una conducta penal como la discriminación, realizada por el empleador injusto que con conocimiento del estado de gravidez de la trabajadora, decide despedirla incurriendo claramente en el tipo penal mencionado en el Código Penal Colombiano, específicamente en los numerales 134 A y su agravación punitiva contenida en el artículo 134 C del mimo Código penal mencionado.

La metodología escogida para desarrollar el presente artículo radica principalmente en proponer la explicación de ciertos objetivos de investigación, tales como, mostrar selectos estándares internacionales sobre el tema; mostrar la legislación interna que se ha construido desde los anteriores parámetros para contribuir en la: "Construcción del conocimiento científico sobre la prevalencia de la violencia de género contra las mujeres en el ámbito laboral" (Frías, 2011); proponer bajo las reglas de la criminología y la psicología social, el porqué de la importancia en la investigación del delito de discriminación como una solución para el déficit de protección propuesto.

Igualmente, se presentarán diferentes definiciones del término discriminación por embarazo, así mismo se pretende explicar de manera sucinta, cómo es que la reparación económica es insuficiente frente al delito de discriminación y las consecuencias reales de dichas reparaciones frente al impulso de la investigación penal.

Una vez determinados los anteriores aspectos investigados, se procederá a hacer un análisis comparativo entre la legislación existente frente a las medidas de protección que cada una proporciona contra el delito de discriminación en el ámbito penal y al mismo tiempo, a compararla con la legislación existente y la jurisprudencia producida alrededor del tema de la protección en materia laboral de la trabajadora embarazada, determinando algunas de las principales directrices que jurisprudencialmente han proporcionado las cortes, frente a la resolución de litigios que se producen cuando un empleador despide a una trabajadora gestante por motivo de su embarazo.

\section{Antecedentes del fenómeno de la Discriminación}

A nivel internacional la discriminación en sus inicios ha sido tratada, desde el punto de vista del racismo, especialmente desde el holocausto nazi cuando por motivos étnicos, se segregaron pueblos judíos lo cual le añade un desarrollo al tema de la discriminación, que nos sirve para iniciar la presente investigación, que versa sobre la discriminación por género. A continuación, veremos algunas definiciones que se han venido acuñando sobre el término discriminación, desde diferentes vertientes del conocimiento normativo:

\section{Tratamiento de la Discriminación desde los estándares internacionales}

Desde la Declaración Universal de Derechos Humanos (Asamblea General. 1948), en su artículo 7, se ha reglado lo siguiente:

Artículo 7 Todos son iguales ante la ley y tienen, sin distinción, derecho a igual protección de la ley. Todos 
tienen derecho a igual protección contra toda discriminación que infrinja esta Declaración y contra toda provocación a tal discriminación.

En complemento a la declaración mencionada, se desarrolló la convención internacional sobre la eliminación de todas las formas de discriminación (Convención, 1965) racial donde se explica en el artículo primero que:

Artículo 1. En la presente Convención la expresión "discriminación racial" denotará toda distinción, exclusión, restricción o preferencia basada en motivos de raza, color, linaje u origen nacional o étnico que tenga por objeto o por resultado anular o menoscabar el reconocimiento, goce o ejercicio, en condiciones de igualdad, de los derechos humanos y libertades fundamentales en las esferas política, económica, social, cultural o en cualquier otra esfera de la vida pública.

A su vez, el Comité para la eliminación de la discriminación racial mediante su recomendación general 14 de 1993, reafirmó su punto de vista sobre esta materia como sigue:

Cualquier distinción es contraria a la convención si tiene el propósito o el efecto de menoscabar determinados derechos y libertades. Esto viene confirmado por la obligación que impone a los estados partes el apartado c) del párrafo 1 del artículo 2 de anular cualquier ley o práctica que tenga por efecto crear o perpetuar discriminación racial (Recomendación, 1993:3).

Una vez reconocida la discriminación como una forma de violencia contra la humanidad, por medio de la convención de Belem do Para (Convención. 1994), las Naciones Unidas, amplían dicho concepto a la protección especial que se le reconoce a la mujer de la siguiente manera:

Artículo 5. Toda mujer podrá ejercer libre y plenamente sus derechos civiles, políticos, económicos, sociales y culturales y contará con la total protección de esos derechos consagrados en los instrumentos regionales e internacionales sobre derechos humanos. Los Estados Partes reconocen que la violencia contra la mujer impide y anula el ejercicio de esos derechos. (Convención, 1994. P 5).

En Centro América, el Comité para la eliminación de la discriminación contra la mujer sesión número 36 del siete al 25 agosto 2006 (Cedaw, Mexico. 2006), ha manifestado la preocupación objetiva sobre la condición de embarazo de la mujer trabajadora en México presentando la siguiente recomendación:

30. El Comité reitera su preocupación sobre la situación de los derechos laborales de la mujer en las industrias maquiladoras, en particular la falta de acceso a la seguridad social y la persistencia de prácticas discriminatorias como las pruebas de embarazo. (Cedaw, Mexico. 2006:6)

Ahora bien, se puede apreciar que en América Latina también se han venido adoptando una serie de legislaciones que ordenan la creación de mecanismos de protección contra la discriminación que le proveen a las mujeres una serie de conceptos de protección que previenen los actos discriminatorios especialmente desde los Estados, y en Colombia esto no fue la excepción.

\section{Tratamiento de la Discriminación desde el ámbito interno en Colombia}

La Ley 1257 de 2008, fue la norma con la cual se dictaron normas de sensibilización, prevención y sanción de formas de violencia y discriminación contra la mujer, reformando tanto los códigos penal y de procedimiento penal, recogiendo algunas disposiciones de la legislación internacional que indican las directrices para la prevención de toda forma de discriminación contenidos en la Convención Americana sobre Derechos Humanos. 
Para efectos del presente artículo, se van a tomar algunas de las definiciones específicas sobre los actos discriminatorios contra las mujeres, los cuales están contenidos en los siguientes artículos:

- "Artículo $2^{\circ}$. Definición de violencia contra la mujer. Por violencia contra la mujer se entiende cualquier acción u omisión, que le cause muerte, daño o sufrimiento físico, sexual, psicológico, económico o patrimonial por su condición de mujer, así como las amenazas de tales actos, la coacción o la privación arbitraria de la libertad, bien sea que se presente en el ámbito público o en el privado".

Para efectos de la presente ley, y de conformidad con lo estipulado en los Planes de Acción de las Conferencias de Viena, Cairo y Beijing, por violencia económica, se entiende cualquier acción u omisión orientada al abuso económico, el control abusivo de las finan-zas, recompensas o castigos monetarios a las mujeres por razón de su condición social, económica o política. Esta forma de violencia puede consolidarse en las relaciones de pareja, familiares, en las laborales o en las económicas.

- "Artículo $3^{\circ}$. Concepto de daño contra la mujer. Para interpretar esta ley, se establecen las siguientes definiciones de daño:

a. Daño psicológico: Consecuencia proveniente de la acción u omisión destinada a degradar o controlar las acciones, comportamientos, creencias y decisiones de otras personas, por medio de intimidación, manipulación, amenaza, directa o indirecta, humillación, aislamiento o cualquier otra conducta que implique un perjuicio en la salud psicológica, la autodeterminación o el desarrollo personal..." (Senado, 2008:1-2).

Teniendo en cuenta las normas antes citadas, es necesario destacar que estas cuentan con ciertas directrices de interpretación, las cuales son las siguientes y es de vital importancia mencionarlas, con el fin de sustentar y cumplir a cabalidad el propósito de este artículo de investigación:

“Artículo 4. Criterios de Interpretación. Los principios contenidos en la Constitución Política, y en los Tratados o Convenios Internacionales de derechos humanos ratificados por Colombia, en especial la convención sobre la eliminación de todas las formas de discriminación contra la mujer y la convención interamericana para prevenir, sancionar y erradicar la violencia contra la mujer, las de-más leyes, la jurisprudencia referente a la materia, servirán de guía para su interpretación y

2. Derechos humanos. Los derechos de las mujeres son Derechos Humanos. ...

7. No Discriminación. Todas las mujeres con independencia de sus circunstancias personales, sociales o económicas tales como edad, etnia. Orientación sexual, procedencia rural o urbana, religión entre otras, tendrán garantizados los derechos establecidos en esta ley a través una previsión de estándares mínimos en todo el territorio nacional."

“Artículo $7^{\circ}$. Derechos de las Mujeres. Además de otros derechos reconocidos en la ley o en tratados y convenios internacionales debidamente ratificados, las mujeres tienen derecho a una vida digna, a la integridad física, sexual y psicológica, a la intimidad, a no ser sometidas a tortura o a tratos crueles y degradantes, a la igualdad real y efectiva, a no ser sometidas a forma alguna de discriminación, a la libertad y autonomía, al libre desarrollo de la personalidad, a la salud, a la salud sexual y reproductiva y a la seguridad personal. (Senado. 2008: 4-5). 
Ahora bien, es importante resaltar precisamente las leyes que reglamentan el delito de discriminación en nuestra legislación interna, (ley 1482 de 2011, modificada por la ley 1752 de 2015), la cual se presenta a continuación:

Artículo 134A. Actos de discriminación. El que arbitrariamente impida, obstruya o restrinja el pleno ejercicio de los derechos de las personas por razón de su raza, nacionalidad, sexo u orientación sexual, discapacidad y demás razones de discriminación, incurrirá en prisión de doce (12) a treinta y seis (36) meses y multa de diez (10) a quince (15) salarios mínimos legales mensuales vigentes.

Artículo 134B. Hostigamiento. El que promueva o instigue actos, conductas o comportamientos constitutivos de hostigamiento, orientados a causarle daño físico o moral a una persona, grupo de personas, comunidad o pueblo, por razón de su raza, etnia, religión, nacionalidad, ideología política o filosófica, sexo u orientación sexual o discapacidad y demás razones de discriminación, incurrirá en prisión de doce (12) a treinta y seis (36) meses y multa de diez (10) a quince (15) salarios mínimos legales mensuales vigentes, salvo que la conducta constituya delito sancionable con pena mayor.

“Artículo 134C. Circunstancias de agravación punitiva. Las penas previstas en los artículos anteriores, se aumentarán de una tercera parte a la mitad cuando: (...)

6. La conducta esté orientada a negar o restringir derechos laborales. (...)(Congreso. 2008:143).

Las conductas mencionadas, constituyen el tratamiento del delito de discriminación, el cual según la misma Fiscalía General de la Nación es un delito autónomo, por lo que dicho estamento, le ha emitido la directiva número 15 del 29 julio 2016, por medio de la cual se han establecido las pautas para la persecución penal de los tipos penales discriminaciones y hostigamiento, contenidos en los artículos 134 A 134 B del Código penal.

Así, la FGN ha abordado el tratamiento del delito con en esta directiva, y es así como la fiscalía ha definido al acto de discriminación:

Como aquella conducta actitud o trato, que "pretende-consciente o inconscientemente-, anular, dominar o ignorar a una persona o grupo de personas, con frecuencia apelando a pre concepciones o prejuicios sociales o personales, y que trae como resultado la violación de derechos fundamentales(F.G.N.2016:5).

Ampliando la definición de la discriminación, emitida por la Fiscalía General de la Nación, es posible verificar cual es el bien jurídicamente tutelado con la tipificación del delito de discriminación, el cual no es otro que el derecho a la Igualdad, concordante con el derecho a la vida, a la libertad y a la dignidad.

Así encontramos que en la misma directiva, también se estipula el bien jurídicamente tutelado de la siguiente manera:

La discriminación es la obstaculización o vulneración injustificada de los derechos de una persona o grupo de personas en razón a su sexo, raza, religión, nacionalidad, orientación sexual, etc. es por ello que evitar la discriminación, lejos de ser un asunto de índole exclusivamente política, es una expresión de la obligación de respetar y garantizar el derecho a la igualdad por parte de los estados.

En este sentido, es importante señalar que la discriminación, inexorablemente involucra al derecho a la igualdad del que la normativa internacional y nacional, han derivado el derecho a no ser discriminado. Así, la adopción de tipos penales que busquen sancionar la ejecución de ciertas conductas discriminatorias tendrá como bien jurídico este derecho. (F.G.N. 2016: 5). 
Ahora bien, aquí surge la duda que radica en que, si ¿es posible técnicamente, determinar una línea conectora entre los actos de discriminación y el derecho que tiene la trabajadora embarazada a que en caso de despido por dicho estado de gravidez, se pueda de oficio iniciar investigación penal?, y para ello se puede trasladar nuevamente a la directiva de la F.G.N. número 15, en la cual, se ha desarrollado la manera de ponderar si un acto cotidiano puede constituir delito de discriminación, al vulnerar la igualdad de la personas así:

Debido a que el delito de actos de discriminación contenida en el artículo 134 A del código penal, precisamente desarrolla un mandato internacional y constitucional de protección a quienes han sido tradicionalmente discriminados, siempre será necesario realizar un test estricto de igualdad. Para ello, al vulnerar el tratamiento diferenciado bajo el examen, los fiscales deberán examinar en el caso concreto (C. Const. 2016:3-5).

\section{Pudiendo reflexionarse:}

- Si el fin perseguido por la conducta desplegada por el sujeto activo será legítimo, importante e imperioso.

- Si la medida utilizada era legítima, adecuada y necesaria, es decir que no podía ser reemplazada por otro menos lesiva y

- Si la medida era razonable, es decir, si los beneficios resultantes excedían las limitaciones a los valores y principios involucrados.

Al aplicar estas consideraciones será posible establecer si el tratamiento diferenciado que se dio en el caso concreto careció no de una justificación objetiva y razonable." (FGN,2016:36).

Se puede colegir entonces, de lo mencionado que para que haya una conducta lesiva al derecho de la igualdad debe superar los tres condicionamientos señalados para que no sean considerados como delito. En ese orden de ideas, se está cumpliendo con el ordenamiento jurídico superior extraído los estándares internacionales mencionados, que prohíben la existencia de discriminación positiva.

Una vez, determinados algunos elementos técnicos generales que consideran y definen a la discriminación desde distintos aspectos de la ley tanto nacional como internacional, desde el campo constitucional y penal, ahora se hará un acercamiento a la protección que brindan las jurisdicciones laboral y constitucional a la maternidad.

La Ley 1826 de enero de 2017. Por medio de la cual se establece un procedimiento penal especial abreviado y se regula la figura del acusador privado.

En esta nueva legislación se proporcionan una serie de herramientas, que simplifican el accionar de la Fiscalía General de la Nación, descargando la obligación probatoria en el acusador privado, figura que antes de la presente ley no existía, coartándole el derecho probatorio a la víctima.

Igualmente proporciona una herramienta procedimental, sobre la manera como se debe adelantar el procedimiento contra el denunciado, especialmente aquel que se oculta del accionar investigativo de la Fiscalía, máxime cuando es de todos sabido, que dicha entidad cuenta con un número limitado de investigadores, para la gran cantidad de casos que llegan a sus estrados.

A continuación, se menciona el aparte de la ley que menciona taxativamente el delito que se trata en el presente artículo: 
Artículo 10. La Ley 906 de 2004 tendrá un nuevo artículo 534, así: Artículo 534. Ámbito de aplicación. El procedimiento especial abreviado de que trata el presente título se aplicará a las siguientes conductas punibles:

1. Las que requieren querella para el inicio de la acción penal.

2. Lesiones personales a las que hacen referencia los artículos 111, 112, 113, 114, 115, 116, 118 y 120 del Código Penal; Actos de Discriminación (C. P. Artículo 134A), Hostigamiento (C. P. Artículo 134B), Actos de Discriminación u Hostigamiento Agravados (C. P. Artículo 134C), ....

Artículo 535. Integración. En todo aquello que no haya sido previsto de forma especial por el procedimiento descrito en este título, se aplicará lo dispuesto por este código y el Código Penal. (Ley 1826.2017).

\section{Protección reforzada de la maternidad desde la jurisdicción laboral}

Desde el Código laboral, se ha desarrollado la protección de la trabajadora en estado de gravidez, específicamente en el artículo 239 del código sustantivo del trabajo, que contiene la siguiente reglamentación:

Artículo 239. Prohibición de despedir. Modificado por el art. 35 de la Ley 50 de 1990, Modificado por el art. 2, Ley 1468 de 2011(LEY 1468 DE 2011). Modificado por el art. 2, Ley 1822 de 2017 (Ley 1822 de 2017).

1. Ninguna trabajadora podrá ser despedida por motivo de embarazo o lactancia sin la autorización previa del Ministerio de Trabajo que avale una justa causa. (Corte Constitucional C-005 de 2017).

2. Se presume el despido efectuado por motivo de embarazo o lactancia, cuando este haya tenido lugar dentro del período de embarazo y/o dentro de los tres meses posteriores al parto. (http://www. alcaldiabogota.gov.co/sisjur/normas/Norma1.jsp?i=33104).

La existencia de la anterior normatividad ha tenido como consecuencia un abundante desarrollo jurisprudencial, especialmente desde la protección constitucional para con la trabajadora en estado de embarazo, lo cual ha conllevado a que dicha madre prefiera la protección de sus derechos desde la jurisdicción constitucional y la jurisdicción laboral, por su inmediatez, jurisdicciones en las cuales se ha hecho efectiva la protección de los derechos con los siguientes pronunciamientos jurisprudenciales:

La estabilidad laboral reforzada en Colombia, es un tema innovador que trae consigo una protección constitucional en el empleo a un determinado grupo de personas, que es considerada por la Carta Política como personas de especial protección y/o personas en estado de debilidad manifiesta, entre ellos se encuentra el trabajador discapacitado o disminuido en su salud como también la mujer en estado de embarazo.

.... El Código Sustantivo del Trabajo, desde antaño con su expedición, previó una protección legal a la mujer en estado de gravidez y dedica un capítulo completo en su articulado a tal grupo de mujeres.

... La Corte Constitucional, como máximo órgano del estado encargado de interpretar y salvaguardar la Constitución no ha sido ajeno a esta temática, y ha proferido varias Providencias donde se manifiesta la forma en que la Corporación aplica e interpreta la protección a la Estabilidad Laboral Reforzada de la mujer en estado de embarazo y del trabajador discapacitado. (Botello.2013:3). 
Para el desarrollo de este artículo se ha escogido el análisis específico de la sentencia de unificación SU-070 13/02/2, la cual por ser de unificación, configura el precedente jurisprudencial de interpretación, en la protección de la maternidad.

\section{Jurisprudencia de interés, la sentencia Su-070/2013}

En esta sentencia se puede ver cómo a la trabajadora en estado de gestación que ha sido despedida por su estado de embarazo, se le brindan una gran cantidad de herramientas legales para que proteja sus derechos fundamentales, tales como: el derecho a la vida, a la libertad, al trabajo, a la igualdad etc., que tienen una extracción directa tanto de las normas internacionales, como de la misma constitución que los ha adoptado y aceptado el carácter de fundamental de los derechos mencionados, especiales para el desarrollo integral no solamente de la mujer, sino de la familia como eje principal del desarrollo social.

Pero, el problema que se pretende revisar en el presente artículo está fundado, en que toda la protección mencionada, repara económicamente a la madre trabajadora, pero no tiene en cuenta, consecuencias más delicadas para el empleador que incurre en el injusto, las cuales al ser articuladas con la ley penal, podrían servir como antídoto definitivo, para que los empleadores, no despidan a las trabajadoras en estado de gravidez.

\section{Las cifras, análisis estadístico e hipótesis}

Por medio de derecho de petición presentado a la página web oficial de la Fiscalía General de la Nación, mediante radicado No. 20176170497512, se le realizaron entre otras, las siguientes preguntas a la entidad:

1. ¿Tiene la Fiscalía estadísticas sobre las investigaciones relacionadas con el delito de discriminación y de ellas cuántas han sido pre acordadas, cuántas han llegado a juicio condenatorio y cuantas han sido derrotadas en juicio?...

2. ¿Alguna vez, ha existido una compulsa de copias por delito de discriminación, de un juez laboral, o de cualquier otra disciplina, por la presunta comisión de un delito de discriminación enmarcado en la resolución de un litigio que se resuelva en jurisdicción diferente a la penal?...

Dichos interrogantes fueron contestados mediante el oficio radicado No. 20171400001071 y No. 06/06/2017, donde se responde lo siguiente:

1. R/ El Sistema información "Sistema penal oral acusatorio" (FGN. 20171400001071) (“SPOA) registra, en el período de 01/12/2011 a 10/05/2017, por el delito de actos de discriminación (Art, 134 A C.P.) 651 investigaciones penales (El conteo reportado incluye todos los tipos de entradas registrados en la Fiscalía General de la Nación, es decir por denuncias, de oficio, por petición especial, rupturas procesales, etc. Fuente: No. 20171400001071 y No. 06/06/2017. Pg 2.). De esas investigaciones, 1 cuenta con sentencia condenatoria, en 2 fue celebrado un preacuerdo entre la FGN y el procesado, y a la fecha no ha sido registrada ninguna sentencia absolutoria.

2. R/ El sistema de información SPOA registra ocho investigaciones penales por el delito de actos de discriminación (Art, 134 A C.P.) que ingresaron a la FGN por compulsa de copias de otra autoridad, entre el 01/12/2011 y el 10/05/2017. 
Las anteriores respuestas, llevaron al presente autor a una nueva petición radicada bajo el número 20176170597162 de fecha 17/06/2017, donde se realizan las siguientes preguntas aclaratorias:

De las 651 investigaciones mencionadas en la respuesta al interrogante 2 del oficio 20171400001071 del 06/06/2017, ¿cuántas investigaciones del delito de discriminación provienen de oficio de la jurisdicción laboral, cuando en dicha jurisdicción, se ha determinado que el empleador ha despedido a una trabajadora por encontrase embarazada?

1. De las 651 investigaciones mencionadas en la respuesta al interrogante 2 del oficio 20171400001071 del 06/06/2017, ¿cuántas investigaciones del delito de discriminación provienen de oficio de la jurisdicción constitucional, cuando vía tutela, se ha determinado que el empleador ha despedido a una trabajadora por encontrarse embarazada?

2. ¿Han tenido denuncias directas de parte de mujeres embarazadas despedidas presuntamente por el embarazo, del delito de discriminación?

3. ¿Han tenido denuncias directas de parte de mujeres embarazadas no contratadas por su estado de embarazo, del delito de discriminación?

4. ¿Ha existido algún tipo de programa o capacitación dictada por la Fiscalía General de la Nación, al Consejo Superior de la Judicatura o a jueces de alguna jurisdicción, para entrenarlos en la remisión de oficio, cuando se encuentran frente a delitos de discriminación ejercidas contra una trabajadora embarazada?

Nuevamente la Fiscalía General de la Nación, de manera muy amable, responde los anteriores interrogantes bajo el radicado No. 20171400001251, con el oficio No. 30/06/2017, donde nos indica:

De acuerdo con lo ya señalado la respuesta 201714000001071 del 06/06/2017, en total existen ocho investigaciones por el delito actos discriminación (art. 134 A C. P.) Desde su vigencia, que ingresaron a la Fiscalía General de la Nación ("FGN") por compulsa copias. De las cuales siete corresponden a compulsas de otro despacho del fiscal de la FGN, y una compulsa de la judicatura.

En relación con su pregunta sobre el número de denuncias recibidas por la FGN de víctimas mujeres en estado de embarazo, que no fueron contratadas o fueron despedidas por el embarazo, el sistema información de la entidad no cuenta con la variable solicitada. Sin embargo, con el fin de dar respuesta a su solicitud se realizó una búsqueda en el relato de los hechos de las investigaciones que adelanta la FGN por el delito de actos discriminación (art. 134 a C.P.), con las palabras clave "embarazo", "embarazada", "gestante" y ninguna corresponde las situaciones fácticas preguntasen su solicitud... al revisar las 11 noticias criminales que tienen en el relato de los hechos algunos de las palabras mencionadas, ninguna hace referencia actos de discriminación por despido o falta de contratación por el Estado de embarazo.

Finalmente, a la fecha la FGN no desarrolla ningún programa o capacitación con sus funcionarios sobre la remisión de oficio por delito de actos de discriminación en contra de una trabajadora embarazada. En relación con las capacitaciones dictadas a los funcionarios del Consejo Superior de la Judicatura y a jueces de la República la pregunta era ser dirigida dichas en la dicha entidad, pues la FGN desconoce los procesos adelantados por esta. (F.G.N. 2017:2).

De lo mencionado, se puede llegar a configurar los siguientes análisis estadísticos de las respuestas emitidas por la FGN, respecto a las 651 denuncias por delito de discriminación: 
i. Solamente $0.15 \%$ han tenido sentencia.

ii. El $0.30 \%$ han sido preacordadas.

iii. El 1.22\% de las denuncias se han convertido en investigaciones por el delito de discriminación, representadas en 8 investigaciones.

iv. De las anteriores investigaciones y con relación a la totalidad de denuncias, el $1.07 \%$ de las investigaciones, han llegado por compulsa de copias de otros despachos de fiscalía, posiblemente por haberse iniciado en la investigación de otros delitos, no contemplados como discriminación por el denunciante; mientras que el $0.15 \%$ de las denuncias, fueron compulsadas por la judicatura, pero no específicamente de la jurisdicción laboral.

Considerándose entonces, de las anteriores conclusiones numéricas y estadísticas las siguientes hipótesis:

- Dentro del sistema de reparto de la FGN, se deben priorizar o conectar parámetros tales como, trabajadora en estado de embarazo, despido, condena en proceso laboral o condena en tutela, con el delito de discriminación mencionado en el artículo 134 C del Código Penal, para que dicha condena automáticamente active la jurisdicción penal.

- La sensibilización del funcionario de la FGN, frente al delito de discriminación es un elemento muy importante para el trámite de las denuncias.

- Los casos laborales, que definen un despido injusto contra una trabajadora embarazada, en los cuales se hubiere determinado que el despido se produjo por el estado de gravidez de la trabajadora, no han producido ninguna compulsa de copias de oficio a la Fiscalía General de la Nación, por el posible delito de discriminación.

- Partiendo del supuesto de conocer el delito de discriminación tipificado en la ley penal, las trabajadoras embarazadas que hubieran sido despedidas injustamente por su estado de embarazo no recurrieron a la jurisdicción penal a denunciar el delito.

- La trabajadora embarazada, despedida por su estado de gravidez, que hubieran obtenido sentencia favorable e indemnización positiva según la ley o la sentencia de su caso específico, han quedado satisfechas con la indemnización económica y ni sus abogados, ni ellas, desearon compulsar copias a la FGN.

- Los despidos sin justa causa de las trabajadoras en estado de embarazo siguen siendo parte importante de los litigios que se presentan en Colombia, ante la jurisdicción laboral.

Estas últimas hipótesis, que son basadas en las cifras estadísticas calculadas desde las respuestas emitidas por parte de la FGN, son las que permiten proponer la siguiente pregunta: El conocimiento del vínculo entre la ley laboral y la ley penal, por una posible conducta de discriminación, en la que incurriría el empleador que despide a una mujer embarazada solo por su estado de gravidez, quien quedaría con el antecedente penal de ser encontrado culpable de dicho delito, ¿puede servir como argumento para que los empleadores desistan del despido de la trabajadora?

Para responder a las complejidades que propone el anterior interrogante, me propongo abordar el tema del delito de discriminación, desde la disciplina sociológica de la criminología y desde la psicología social, de las conductas injustas que ejerce el empleador en contra de la trabajadora embarazada, la cual podría servir como fundamento para justificar el fin del artículo. 
Es importante conectar lo que la FGN contestó, con el contexto del artículo, pues según lo estudiado, a lo largo de estas páginas:

- Hay justificación legal para la existencia del presente estudio tanto desde el punto de vista penal, como del laboral y en respaldo de ambos, desde los derechos humanos.

- Existe un vacío en el ejercicio de tramitar al interior de la FGN, la denuncia por el delito de discriminación proviniendo de un despido a una trabajadora embarazada y eso se refleja en la política criminal aplicada a la categorización del delito, asunto que conlleva al estudio de las políticas criminales que aplica la FGN.

- Según la contestación del D.P. número 20171400001071 del 06/06/2017, que sirve como base del presente artículo, hay una política de género y enfoques diferenciales, aplicado en la FGN que reconoce que "La importancia de la aplicación transversal del enfoque de género responde a los compromisos adquiridos por el Estado colombiano a nivel internacional en los convenios de Nairobi 1985, Rio de Janeiro 1992, Viena 1993, El Cairo 1994, Copenhague 1995, Beijing 1995 e incluso la declaración del Milenio del año 2000" (FGN 20171400001251. 30/06/2017).

Sin embargo, dicho enfoque no reconoce al embarazo como un estado especialísimo de la mujer, que no constituye una discapacidad, pero sí constituye una capacidad única que representa cierto estado de vulnerabilidad, lo cual en este último apartado del artículo, se tratará mediante la exposición de razones y fundamentos de criminología que a continuación serán expuestos.

4. Desde la criminología el delito de discriminación: la fórmula para invertir la relación de poder a favor de la trabajadora embarazada

Bajo lo estudiado hasta el momento es posible encontrar que la política pública que utiliza la FGN se circunscribe en mayor medida al cumplimiento político de pactos internacionales, por lo tanto, desde la minería del texto base de la investigación, se encuentra la necesidad de sugerir una complementación a dicha política y para ello será de suma importancia, acudir a la criminología, para justificar, la existencia de una política diferencial en favor de una trabajadora en estado de embarazo, por lo menos para articular y mejorar el proceso de denuncia.

A medida que se ha venido realizando la presente investigación, se ha podido determinar que para efectos de explicar el porqué de la necesidad de vincular el concepto de delito a la protección que ya brinda las jurisdicciones constitucional y laboral, a la mujer embarazada que es víctima de despido, por ende, del delito de discriminación, es necesario incurrir en las herramientas de la criminología, disciplina adoptada e interiorizada por el Derecho Penal, ya que según García-Pablos se indica: 
la función básica la criminología consiste en informar a la sociedad y a los poderes públicos sobre el delito, el delincuente, la víctima y el control social aportando un núcleo de conocimientos más seguro y contrastado que permita comprender científicamente el problema criminal, prevenirlo e intervenir con eficacia y de modo positivo en el hombre delincuente."(García-Pablos. 1988, P 71 y ss).

Para explicar la necesidad de complementación de la Política Criminal aplicada por la FGN mencionada, se utilizara la Teoría del etiquetamiento, la cual justifica la existencia de reglas diferenciales para grupos sociales diferentes así:

Siguiendo una línea semejante, H BECKER explica que todo grupo social hacer reglas para percibir actuaciones como correctas e incorrectas, de donde desprende que el hecho fundamental de la desviación estriba en que ésta es creada por la sociedad, no en un sentido de que sus causas se encuentren en la situación social o en factores sociales, sino en el de que los grupos sociales generan la desviación al confeccionar las reglas cuya infracción la constituye y al aplicar dichas normas a determinadas personas. Desde este punto de vista la desviación no es una cualidad del acto cometido por la persona sino una consecuencia de la aplicación que los otros hacen de las reglas y de las sanciones para un ofensor. En fin, agrega Becker, aparte de lo anterior, el que un acto sea desviado depende de quién vulnera las reglas, contra quién y cómo reaccionan los demás." (Pérez, 1994. P 88).

Esto, es lo que sucede al darle prelación a la tutela y al derecho laboral y es aquí donde se genera el déficit de protección buscado en el presente artículo, por ello, que el delito mencionado en el artículo $134 \mathrm{C}$ del Código Penal, no representa ningún factor de interés para el ente investigativo de la nación, pero según la percepción actual, esta teoría, también sirve para justificar la existencia de una complementación a la Política Criminal aplicada por la FGN, especialmente, para evaluar el ejercicio de denuncia proveniente de una causa típicamente laboral, en favor de una trabajadora especialísima, por su estado de gravidez.

Lo es, porque desde el entendido de la teoría mencionada, se ha venido soslayando la aplicación del artículo $134 \mathrm{C}$ del Código penal, precisamente porque la jurisdicción constitucional y laboral, han cooptado la resolución de los despidos de las trabajadoras embarazadas, sin tener en cuenta la posibilidad implícita del delito de discriminación, adoptando una posición curativa del problema, lo cual pasa cuando ya se presenta el despido, pero si se le proporciona a la trabajadora en estado de gravidez, además de las prevenciones labores y constitucionales, un argumento legal de refuerzo que también contiene la ley penal en el artículo $134 \mathrm{C}$, por medio de reglas de trámite de denuncias ante la justicia penal, es posible que la aplicación de la ley ante la jurisdicción penal, sea de mayor impacto al empleador, por ende, prevenga la existencia de estas conductas, pues un alto funcionario que ejerza subordinación sobre una trabajadora embarazada como podría ser un representante legal, o un director de gestión humana, o gerente, acepta el pago de una indemnización, pero si además viene con un antecedente penal, la prevención seria completa. 
Por eso, es que se sugiere que la FGN, en el ejercicio de reparto, debería ampliar los conectores del tipo relacionados en el art $134 \mathrm{C}$ del C.P., como forma práctica de mejoramiento del acceso a la justicia, además, deberían ampliar la política criminal de la FGN (Resolución 368. 2012 y Resolución 450 de 2012), para que exista una justificación legal del impulso procesal de la denuncia por discriminación y así las condenas en dicha jurisdicción sean efectivas, pues ni las actuales denuncias han llegado a sentencia alguna.

Finalmente, las posiciones mencionadas obtienen mayor importancia en la actualidad de la historia de Colombia, ya que parte del descenso en la natalidad colombiana, se basa en la negativa de las mujeres para ser contratadas, por el riesgo de quedar en embarazo, lo cual implica una verdadera necesidad en prevenir que una joven mujer trabajadora, renuncie a su derecho de ser madre, por poner en riesgo su estabilidad laboral, al ver que la misma OIT ha mencionado:

Artículo 8 1. Se prohíbe al empleador que despida a una mujer que esté embarazada, o durante la licencia mencionada en los artículos 4 o 5, o después de haberse reintegrado al trabajo durante un período que ha de determinarse en la legislación nacional, excepto por motivos que no estén relacionados con el embarazo, el nacimiento del hijo y sus consecuencias o la lactancia. La carga de la prueba de que los motivos del despido no están relacionados con el embarazo o el nacimiento del hijo y sus consecuencias o la lactancia incumbirá al empleador. 2. Se garantiza a la mujer el derecho a retornar al mismo puesto de trabajo o a un puesto equivalente con la misma remuneración, al término de la licencia de maternidad." (Convenio 183, 2000).

Bajo lo expuesto es posible pensar que aunque es bastante odioso para cualquiera, hay cierta razón económica en cuanto al riesgo que podría constituir para una empresa pequeña, el emplear a una trabajadora y que ella, entrara en embarazo, le implicara el nombramiento de el reemplazo de la misma y además el pago del sueldo de ella.

En este punto del artículo, es posible mencionar que esta situación, puede solucionarse casi de manera definitiva, con una ley que comparta entre el empleador y el Estado, la carga prestacional de la trabajadora en estado de embarazo, y además la misma Nación, asuma el pago de al menos el $50 \%$ del salario en la época de la licencia de maternidad, con el compromiso de que el empleador garantice a la madre trabajadora 3 años más de vinculación laboral después del alumbramiento así, Colombia obligará al empleador no solamente a mantenerle el empleo a la trabajadora, sino sería un factor motivador de la vinculación de trabajadoras, inclusive en estado de embarazo, lo cual, además podría servir como un factor de calificación positivo para la contratación Estatal, por buenas prácticas empresariales.

Conclusiones 
Existe suficiente material legal, tanto nacional como internacional, para poder catalogar el despido injusto de una trabajadora en estado de embrazo, como un acto de discriminación.

A la fecha, los jueces laborales que han solucionado por vía judicial, conflictos ocasionados por despidos injustificados de trabajadoras en estado de embarazo, no han denunciado de manera oficiosa el delito de discriminación, ejercido por los empleadores, contra las trabajadoras en estado de gravidez.

Las jurisdicciones laborales y constitucionales se han preocupado por resarcir económicamente a las trabajadoras embarazadas despedidas injustamente, sin tener en cuenta que la jurisdicción penal, contempla al delito de discriminación, como una posible solución para conjurar el desbalance psicosocial que existe en la relación empleador - trabajadora. Esto indica que la sociedad, no está controlando el castigo social de la conducta y solo se está preocupando por procurar un pago económico a favor de la empleada. ¿Qué pasa con su dignidad y la de su familia?

Desde las teorías de la criminología y desde la génesis de los derechos humanos, es posible concluir la importancia de que el Estado priorice la investigación y persecución penal del empleador que por discriminación despide a la trabajadora embarazada, por cuanto es el mejor medio de escarnio y castigo público, lo cual implicaría una evidencia real de que la sociedad, en verdad se está preocupando por la vigilancia de dicha discriminación, ya que la indemnización monetaria, solo corresponde al sosiego de un interés privado, mas no le demuestra al género femenino que la sociedad sí se preocupa por salvaguardar su integridad de manera reforzada.

Para que un juez laboral pueda concordar un despido injusto de una trabajadora embarazada, con el delito de discriminación, debe someter la conducta del empleador al siguiente examen:

a. Si el fin perseguido por la conducta desplegada por el sujeto activo será legítimo, importante e imperioso.

b. Si la medida utilizada era legítima, adecuada y necesaria, es decir, que no podía ser reemplazada por otra menos lesiva.

c. Si la medida era razonable, es decir, si los beneficios resultantes excedían las limitaciones a los valores y principios involucrados.

Entonces, en la justicia colombiana si el juez laboral verifica que con su conducta el empleador cometió actos de discriminación, debe enviar la investigación de oficio a la fiscalía para que se investigue el delito de discriminación, pero actualmente no pasa.

Desde el análisis de los aspectos estudiados se sugiere que dentro del sistema de reparto de la FGN, se deben priorizar o conectar parámetros tales como: trabajadora en estado de embarazo, despido, condena en proceso laboral o condena en tutela, con el delito de discriminación mencionado en el artículo $134 \mathrm{C}$ 
del Código Penal, para que dicha condena automáticamente active la jurisdicción penal.

La sensibilización del funcionario de la FGN, frente al delito de discriminación es un elemento muy importante para el trámite de las denuncias, por ello, es necesario dar especial entrenamiento al funcionario de la importancia de la priorización del estado de gravidez de una trabajadora, más cuando dicho tipo atenta contra la especie en general.

Por todo lo anterior se puede mencionar que la ley penal, actualmente si tiene bien contemplado el tratamiento del delito de discriminación, pero aún falta el acoplamiento de las otras jurisdicciones especialmente cuando los casos ingresan a otras jurisdicciones diferentes a la penal. 


\section{INCISO}




\section{INCISO}




\section{INCISD}

ISSN: 1794-1598 


\section{INCISO}




\section{INCISO}




\section{INCISO}

